\title{
A Comparative Study of Smooth Insertion of Laryngeal Mask Airway with Propofol and Thiopentone Combined with Midazolam
}

\author{
Syeda Nafisa Khatoon ${ }^{1 *}$ \\ Md.Rezaul Hoque Tipu ${ }^{1}$ \\ Sanjida Hasan ${ }^{2}$ \\ KM Baki Billah ${ }^{1}$ \\ Gulshan Ara Chowdhury ${ }^{1}$ \\ A K M Shamsul Alam \\ 'Department of Anesthesiology \\ Chittagong Medical College \\ Chittagong, Bangladesh. \\ ${ }^{2}$ Department of Anesthesiology \\ Southern Medical College \\ Chittagong, Bangladesh.
}

\section{${ }^{*}$ Correspondence to:}

Dr. Syeda Nafisa Khatoon

Assistant Professor

Department of Anaesthesiology

Chittagong Medical College

Chittagong, Bangladesh.

Mobile : +8801823050719

E mail: syedanafisakhatoon1@gmail.com

www.banglajol.info/index.php/CMOSHMCJ

\begin{abstract}
Background: Successful insertion of Laryngeal Mask Airway (LMA) requires sufficient depth of anesthesia and depression of airway reflexes to avoid gagging, coughing and laryngeal spasm. The LMA is popular because it is easy to insert and it provides a secure airway for the patients who breathe spontaneously. Indeed, the intravent LMA instruction manual specifically recommends propofol for induction of anesthesia during LMA insertion. As a matter of fact Propofol and LMA insertion has become synonymous. However, there are some problems related to the use of propofol, for example, relatively high cost. This observational study was conducted to compare efficacy and safety of propofol and thiopentone -midazolam in smooth insertion of LMA and the hemodynamic changes over time in both groups. Methods: The study was done in the Department of Anesthesiology, Chittagong Medical College from July, 2012 to December, 2013. All the patients scheduled for elective surgical procedures under general anesthesia fulfilling the inclusion criteria, were the study population. Data was analyzed by computer based software SPSS- 21 . Results: Overall LMA insertion condition was improved better by the use of midazolam with thiopentone sodium (Group B) than propofol (Group A). The drug regime used in group A (Propofol) was expensive than group B (midazolam with thiopentone sodium) with indifferent hemodynamic stability in both groups. Mean ages of patients were 32.43 years \pm SD- 10.67 years in group A and 33.5 years \pm SD10.63 years in group B. Conclusion: In the perspective of our study, for smooth insertion of LMA midazolam-thiopentone sodium regime is cheaper and can be effectively and safely used over propofol regime.
\end{abstract}

Key words: Laryngeal Mask Airway (LMA); Smooth insertion; Propofol; Midazolam-Thiopentone sodium.

\section{INTRODUCTION}

The Laryngeal Mask Airway (LMA) is an ingenious supraglottic airway device that is designed to provide and maintain a seal around the laryngeal inlet for spontaneous ventilation and allow controlled ventilation at modest levels of positive pressure ${ }^{1}$. The use of LMA is well established in anesthetic practice. LMA obviates the need for tracheal intubation during anesthesia ${ }^{2}$. Successful insertion of LMA requires sufficient depth of anesthesia and depression of airway reflexes to avoid gagging, coughing and laryngeal spasm. The Laryngeal Mask Airway (LMA) is popular because it is easy to insert and it provides a secure airway for the patients who breathe spontaneously ${ }^{3,4}$.

Indeed, the Intravent LMA instruction manual specifically recommends propofol for induction of anesthesia during LMA insertion ${ }^{5}$. As a matter of fact Propofol and LMA insertion has become synonymous. However, there are some problems related to the use of propofol, for example, relatively high cost of the drug and easy insertion was seen only in about $62 \%$ of patients ${ }^{6}$. 
Thiopentone has been assessed for its usefulness in aiding LMA insertion in un-pre-medicated patients but produces less satisfactory conditions than propofol due to the fact that Thiopentone sodium does not attenuate laryngeal reflexes as that of propofol ${ }^{7}$. To overcome the disadvantages, a variety of supplementary drugs were used to find a compound which eases LMA insertion, for example midazolam, alfentanil ${ }^{8}$. Another study evaluated the response to insertion of the Laryngeal Mask Airway (LMA) following either propofol $2.5 \mathrm{mg} / \mathrm{kg}$ or thiopentone $5 \mathrm{mg} / \mathrm{kg}$ in two groups of patients found propofol is superior to thiopentone as an induction agent for insertion of the Laryngeal Mask Airway (LMA) ${ }^{7}$.

Laryngeal Mask Airway (LMA) insertion with the use of propofol as a sole induction agent for anesthesia, the incidence of success rate was not satisfactory. Many co-induction drugs had been used to improve the insertion condition in other studies, as investigated the use of midazolam (M) or mini-dose succinylcholine (S) as a co-induction agent with propofol to facilitate LMA insertion in surgery patients. Midazolam had the advantage of reducing the dose of propofol and providing hemodynamic stability ${ }^{2,8,9}$. Mini-dose of succinylcholine had the disadvantage that it cannot be used in patients with plasma cholinesterase deficiency and should be avoided in patients prone to myalgia ${ }^{11,12}$. This study compared the ease of LMA insertion using thiopentone with midazolam and propofol subjected to elective surgical procedures under general anesthesia.

\section{MATERIALS AND METHODS}

The study was a prospective, double-blind randomized trial conducted in the Department of Anesthesiology in collaboration with different Surgical and Obs/Gyn. units of Chittagong Medical College Hospital from July, 2012 to December, 2013. All the patients scheduled for elective surgical procedures under general anesthesia fulfilling the inclusion criteria, were the study population.

Data was collected by a pre-tested and pre designed data collection form from a total of 64 patients who gave written consent, met the enrollment criteria and selected randomly by lottery method for inclusion in the study. Before inclusion, consent form was read aloud to the patients and his right to withdraw from the study, at any stage, for any reason was mentioned. During the study possible risks and the rescue measures arranged to save the patient from any adverse situation were explained. In the pre-anesthetic check-up room patients were examined thoroughly and those who fulfilled the inclusion criteria were informed in detail about the study procedure \& only those patients were selected, who agreed to participate.
The demographic variables were age, sex and weight. The preoperative variables were blood pressure, heart rate, coexisting diseases. The per-operative variables were jaw relaxation, head- extension, coughing, gagging, tearing/blinking, pt's movement and laryngospasm. Hemodynamic variables included blood-pressure, heart rate, $\mathrm{SpO}_{2}$.

\section{Inclusion criteria}

i) Patients scheduled for elective surgical procedures when LMA insertion was indicated

ii) Adult patients of 18 - 50 yrs of age.

\section{Exclusion criteria}

i) Patients undergoing emergency operation/ Hypertensive patients

ii) Tracheostomized patients

iii) Patients not consenting to the procedure.

\section{RESULTS}

A total of 64 patients undergoing routine operations under general anesthesia were divided into two groups-Group A received Group-A received Inj, Propofol $(2.5 \mathrm{mg} / \mathrm{kg})$ Group-B received Inj. Midazolam $(0.05 \mathrm{mg} / \mathrm{kg})$ and Thiopentone $(5 \mathrm{mg} / \mathrm{kg})$. The prescribed variables and hemodynamic parameters were recorded in the case record form.

Observable differences of all forms of jaw relaxation were found between the patients from group A (Excellent- $56.70 \%$, Good- 33.30\%, Poor- 10.00\%) and group B (Excellent$81.30 \%$, Good- $15.60 \%$, and Poor- $03.10 \%$ ). There were also a measurable difference for head extension between the groups as observed in group A (Excellent- 43.30\%, Good- 50.00\%, Poor$6.70 \%$ ) and group B (Excellent- 71.90\%, Good- 28.10\%, and Poor- $0.00 \%$ ). The number of patients with tearing/blinking, gagging, coughing, laryngospasm and patient movement were not distinctly different between group A and B (Table 1).

In $28(93.3 \%)$ patients from group A, LMA was successfully inserted after first attempt and $04(06.7 \%)$ patients required second attempt. $27(84.4 \%)$ patients from Group B required single attempt while $05(15.6 \%)$ patients required second attempt for LMA insertion which was not significantly different between the groups (Table 2).

The overall insertion condition of LMA was graded excellent in $13(40.63 \%)$ patients in group A and in $16(50.00 \%)$ patients in group B. On the contrary, good LMA condition was observed in 17 (53.13\%) patients from group A and 15 (46.88\%) patients from Group B with poor condition in $02(06.25 \%)$ patient from group A and 01 (03.13\%) patients from Group B (Figure 2). Significant changes observed in case of systolic and diastolic blood pressure, heart rate and $\mathrm{SpO}_{2}$ over time in 02 groups. $(\mathrm{p}=0.000)$ (Table 3). 


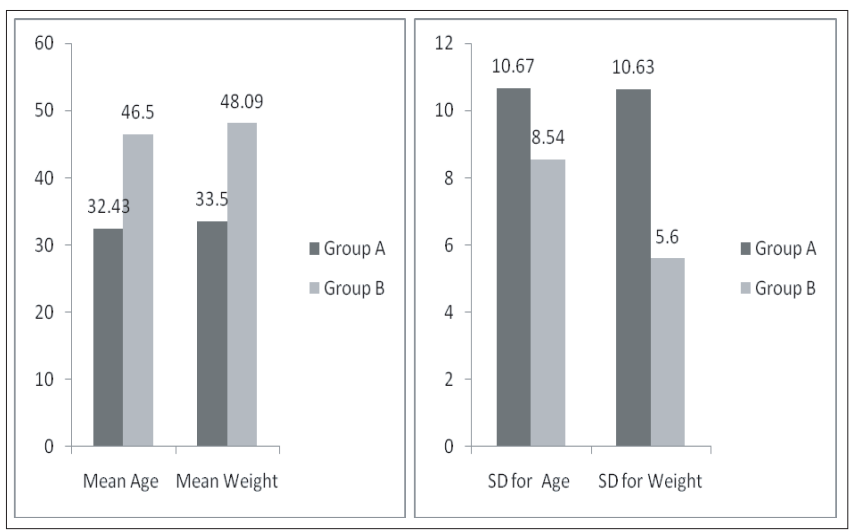

Figure 1: Mean and SD for age and weight in A and B group $(n=64)$

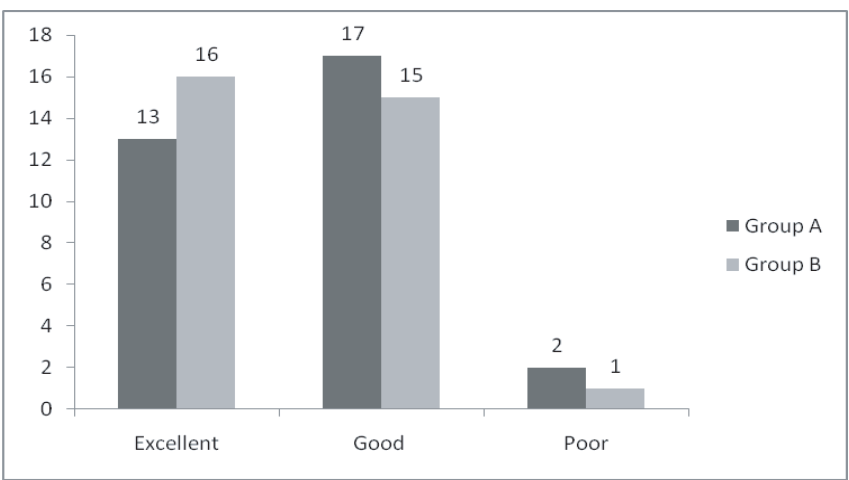

Figure 2: Showing overall insertion condition in A and B group ( $\mathrm{n}=64)$

Table 1: Conditions during LMA insertion

\begin{tabular}{|c|c|c|c|c|}
\hline \multirow[t]{2}{*}{ Parameters } & \multicolumn{2}{|c|}{ Group A (n=32) } & \multicolumn{2}{|c|}{ Group B $(n=32)$} \\
\hline & $\mathbf{n}$ & $\%$ & $\mathbf{n}$ & $\%$ \\
\hline \multicolumn{5}{|c|}{ Jaw relaxation } \\
\hline Excellent & 18 & 56.70 & 26 & 81.30 \\
\hline Good & 11 & 33.30 & 5 & 15.60 \\
\hline Poor & 3 & 10.00 & 1 & 3.10 \\
\hline \multicolumn{5}{|c|}{ Head extension } \\
\hline Excellent & 13 & 43.30 & 23 & 71.90 \\
\hline Good & 15 & 50.00 & 9 & 28.10 \\
\hline Poor & 4 & 6.70 & 0 & 0.00 \\
\hline \multicolumn{5}{|c|}{ Tearing/ eye blinking } \\
\hline Present & 7 & 16.70 & 3 & 9.40 \\
\hline Absent & 25 & 83.30 & 29 & 90.60 \\
\hline Gagging & & & & \\
\hline None & 28 & 87.50 & 28 & 87.50 \\
\hline Mild & 4 & 12.50 & 4 & 12.50 \\
\hline \multicolumn{5}{|c|}{ Coughing } \\
\hline None & 22 & 73.30 & 24 & 75.00 \\
\hline Mild & 10 & 26.70 & 6 & 18.70 \\
\hline Moderate & 0 & 0.00 & 2 & 6.30 \\
\hline \multicolumn{5}{|c|}{ Pt's movement } \\
\hline None & 15 & 46.60 & 24 & 75.00 \\
\hline Mild & 9 & 26.70 & 4 & 12.50 \\
\hline Moderate & 8 & 26.70 & 3 & 9.40 \\
\hline Severe & 0 & 0.00 & 1 & 3.10 \\
\hline \multicolumn{5}{|c|}{ Laryngospasm } \\
\hline None & 30 & 100.00 & 30 & 93.80 \\
\hline Partial & 2 & 0.00 & 2 & 6.30 \\
\hline
\end{tabular}

Table 2 : No. of attempt for LMA insertion

\begin{tabular}{|c|c|c|c|c|c|}
\hline \multicolumn{3}{|c|}{$\begin{array}{l}\text { Attempt for } \\
\text { LMA insertion Group A }(n=32)\end{array}$} & \multicolumn{2}{|c|}{ Group B $(n=32)$} & \multirow[t]{2}{*}{$p$ value } \\
\hline & $\mathbf{n}$ & $\%$ & n & $\%$ & \\
\hline $1^{\text {st }}$ & 28 & 93.3 & 27 & 84.4 & $0.50^{*}$ \\
\hline $2^{\text {nd }}$ & 4 & 6.7 & 5 & 15.6 & \\
\hline
\end{tabular}

*p value reached from chi-square test

Table 3: Hemodynamic comparison between Group A and Group B (n=64)

\begin{tabular}{|c|c|c|c|c|c|c|c|c|c|}
\hline & $\begin{array}{l}\text { Pre i } \\
\text { (Mez }\end{array}$ & & $\begin{array}{l}\text { Post indu } \\
\text { (Mean } \pm\end{array}$ & & $\begin{array}{l}\text { Immedliat } \\
\text { (Mea }\end{array}$ & $\begin{array}{l}\text { LWA } \\
\text { D) }\end{array}$ & $\begin{array}{r}03 \mathrm{mint} \\
(\mathrm{M}\end{array}$ & $\begin{array}{l}\text { er LMI } \\
\text { SD) }\end{array}$ & \\
\hline & Grou & & Group A & un & B Gr & oup 1 & B Grou & roup 1 & \\
\hline & $\begin{array}{l}125.10 \\
\pm 7.99\end{array}$ & $\begin{array}{l}124.84 \\
\pm 3.87\end{array}$ & $\begin{array}{l}119.03 \\
\pm 8.94\end{array}$ & $\begin{array}{l}115.59 \\
\pm 6.88\end{array}$ & $\begin{array}{r}110.03 \\
\pm 19.77\end{array}$ & $\begin{array}{l}112.94 \\
\pm 19.51\end{array}$ & $\begin{array}{r}106.17 \\
\pm 14.79\end{array}$ & $\begin{array}{r}115.94 \\
\pm 8.60\end{array}$ & 0.000 \\
\hline 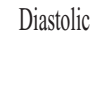 & $\begin{array}{r}76.13 \\
\pm 12.03\end{array}$ & $\begin{array}{r}76.72 \\
\pm 9.90\end{array}$ & $\begin{array}{r}74.23 \\
\pm 2.57\end{array}$ & $\begin{array}{r}72.41 \\
\pm 0.02\end{array}$ & $\begin{array}{r}68.20 \\
\pm 12.17\end{array}$ & $\begin{array}{r}72.06 \\
\pm 3.47\end{array}$ & $\begin{array}{r}66.27 \\
\pm 10.86\end{array}$ & $\begin{array}{r}73.34 \\
\pm 1.96\end{array}$ & 0.000 \\
\hline HR & $\begin{array}{r}85.97 \\
\pm 15.76\end{array}$ & $\begin{array}{r}92.78 \\
\pm 5.00\end{array}$ & $\begin{array}{r}86.37 \\
\pm 4.23\end{array}$ & $\begin{array}{r}91.91 \\
\pm 2.55\end{array}$ & $\begin{array}{r}83.70 \\
\pm 17.69\end{array}$ & $\begin{array}{r}90.13 \\
\pm 3.52\end{array}$ & $\begin{array}{r}79.53 \\
\pm 17.27\end{array}$ & $\begin{array}{r}90.09 \\
\pm 3.83\end{array}$ & 0.000 \\
\hline 12 & $\begin{array}{r}98.93 \\
\pm 1.78\end{array}$ & $\begin{array}{l}99.09 \\
+1.77\end{array}$ & $\begin{array}{r}98.90 \\
\pm 1.84\end{array}$ & $\begin{array}{r}98.97 \\
\pm 1.82\end{array}$ & $\begin{array}{r}98.77 \\
\pm 1.19\end{array}$ & $\begin{array}{r}99.03 \\
\pm 1.86\end{array}$ & $\begin{array}{r}98.57 \\
\pm 0.93\end{array}$ & $\begin{array}{r}99.28 \\
\pm 1.65\end{array}$ & \\
\hline
\end{tabular}

$p$ value calculated by paired ' $t$ ' test

\section{DISCUSSION}

The most commonly used induction agent for LMA insertion continues to be propofol as this agent best obtunds oropharyngeal reflexes. Propofol $(2.5-3 \mathrm{mg} / \mathrm{kg})$ was the induction agent of choice for LMA insertion ${ }^{1}$. Though, there were conflicting reports regarding insertion of LMA with propofol. Studies had shown an incidence of poor insertion condition in $38-60 \%$ patients with standard induction doses (2$3 \mathrm{mg} / \mathrm{kg}$ ) of propofol ${ }^{12}$. Study shown that the drug allow adequate jaw relaxation, prevents laryngospasm but commonly resulted in hypotension ${ }^{6}$.

There was no significant difference in demographic data among the groups. This study was intended to compare the ease of insertion of Laryngeal Mask Airway (LMA) between the study groups. We used propofol $2.5 \mathrm{mg} / \mathrm{kg}$ as induction agent in group $\mathrm{A}$ and midazolam $(0.05 \mathrm{mg} / \mathrm{kg})$ and thiopentone sodium $(5 \mathrm{mg} / \mathrm{kg})$ in group B. The residual upper airway reflexes, which may cause coughing and gagging were a major cause of failed/ difficult LMA insertion. The use of propofol alone in group A was associated with mild gagging in $12.50 \%$ and coughing in $26.70 \%$ patients.

In the present study, the incidence of successful insertion in group A at first attempt was $93.3 \%$ that is closer to $74 \%$ as found in an earlier study ${ }^{7}$. In our study, all the patients received Inj. fentanyl $(1 \mathrm{~g} / \mathrm{kg})$ as pre-treatment, that might explain better 
insertion condition in group A. Benzodiazepines are well known to reduce upper airway reflexes ${ }^{13}$. The use of midazolam with thiopentone (Group-B) was associated with excellent jaw relaxation $(81.3 \%)$ with mild gagging $(12.5 \%)$ and mild coughing (18.7\%) and mild patient movement (12.5\%). Excellent or good insertion condition was observed in $93.76 \%$ patients of group A and $96.88 \%$ patients of group B with $93.3 \%$ patients in group A and $84.4 \%$ patients in group B with successful insertion at first attempt that is in relevance with another study with a higher dose of midazolam $(0.1 \mathrm{mg} / \mathrm{kg})$ in combination ${ }^{14,15}$.

Hemodynamic variables (Systolic \& diastolic blood pressure, heart rate and $\mathrm{SPO}_{2}$ ) were observed in both groups during preinduction, post-induction, immediately after LMA insertion and 03 minutes after LMA insertion. Significant difference was observed over the time $(p<0.05)$ in systolic \& diastolic blood pressure, heart rate and $\mathrm{SPO}_{2}$ but no significant difference was observed between the groups which is compatible with another study $^{10,11}$.

\section{LIMITATIONS}

Small sample size was used in this study, so to generalize the findings further study with larger sample is required.

\section{CONCLUSION}

LMA insertion condition had improved by the use of midazolam with thiopentone sodium (Group B) than propofol (Group A) alone. The drug regime used in group B (Midazolam-thiopentone sodium) is cheaper than propofol as used in group A. In our study hemodynamic stability was observed better in group-B than group A. So, in the perspective of our study, we can conclude that for smooth insertion of LMA midazolam-thiopentone sodium can be effectively and safely used as an alternative to expensive propofol.

\section{DISCLOSURE}

All authors declare no competing interest.

\section{REFERENCES}

1. Brain A. The laryngeal mask - a new concept in air way management. British Journal of Anaesthesia. 1983;55:801-806.

2. Driver, Kinirons, Scalon P. Laryngeal mask airway- optimum time for insertion.Br.J. Anaesthesia. 1997;75: 665.

3. Ali S. Department of Anaesthesia,Zanedan University in Medical Sciences, Zahedan, Iran. 2007;12(2).

4. American Thoracic Society. The journal of American society ofAnaesthesiologists. 2003.

5. Brain AIJ. The intravent laryngeal mask instruction manual: Ed,1-2.1999.

6. Stoneham MD, Bree SEE, Sneyd JR. Facilitation of laryngeal mask insertion, effects of lignocaine given intravenously before induction with propofol. 1995.

7. Scalon P.,Carey M., Power M. and Kioby F. Pts response to LMA insertion after induction of anaesthesia with Propofol orThiopentone.Can.J.Anaesthesia. 1993;40:816-818.

8. Driven J, Wiltshire L, Mills P, Lilly-White N and Howard-Griffin R. Midazolam co-induction and LMA insertion. Anaesthesia. 1996;51:782-784.

9. Driven J, Wilson C, Wiltshire S, Mills P and Howard-Griffin R. Co-induction and LMA insertion: A comparison of thiopentone vs propofol. Anaesthesia. 1997; 52:698-700.

10. Dundee JW, Kawar P, Consistency of action of midazolam. Anaesthesia. 1982; 61: 544-545.

11. Driven, Wiltshire L, Mills P, Lilly-White $\mathrm{N}$ and Howard-Griffin R. Midazolam before induction improves condition for Laryngeal mask insertion. Br.J.Anaethesia. 1995; 75: 664.

12. Christine JC Cheng, Sitaram Raman.Timothy J, Ridgway, Chui Ping Chia. Use of suxamethonium to facilitate LMA insertion. Journal of Anaesthesiology. 2003;6(2).

13. Gill RS. Etomidate shortens the onset time of neuromuscular blockade,Br.J. 1997;69(5):444-446.

14. Yoshinho A HJkawa Y, Maeda M. Patient response to laryngeal mask airway insertion of anaesthesia with propofol or thiopentone. 1993.

15. Bapat P, Joshi RN, Young E, Jago RH. Comparison of propofol versus thiopentone with midazolam or lidocaine to facilitate laryngeal mask. 1996. 